\title{
Milica Medić-Stojanoska*
}

\section{LEKOVI, TIREOSTI MULI ŠUĆI HORMON I CENTRALNI HI POTI REOI DI ZAM}

\begin{abstract}
Apstrakt: Brojni lekovi utiču na tireoidnu funkciju različitim mehanizmima. Širok spektar mehanizama uključuje promene na nivou hipotalamusno-hipofizne osovine, sinteze i sekrecije tireoidnih hormona od strane štitaste žlezde, te metabolizma i delovanja tireoidnih hormona. Mala podgrupa lekova, koja uključuje glukokortikoide, dopamin i dopaminske agoniste, somatostatinske analoge i reksinoide, dovodi do supresije TSH i centralnog hipotireoidizma.Ovaj centralni hipotireoidizam najčešće nije klinički manifestan i ne zahteva lečenje. Samo reksinoidi uzrokuju klinički jasan hipotireoidizam koji zahteva terapiju. Netireoidne bolesti takođe dovode do supresije TSH i centralnog hipotireoidizma kompleksnim mehanizmima. On postaje klinički manifestan ako se u lečenju netireoidnih bolesti koriste glukokortikoidi i dopamin kada treba razmotriti i potrebu lečenja nastalog hipotireoidizma. U ovom radu se analiziraju mehanizmi delovanja lekova koji dovode do centralnog hipotireoidizma i klinički značaj ovih uticaja.
\end{abstract}

Ključne reči: lekovi, TSH, centralni hipotireoidizam

\begin{abstract}
A great number of drugs affect thyroid function by different mechanisms. A wide range of mechanisms include modifications to the hypopthlamo-pituitary axis, synthesis and secretion of thyroid homone by thyroid and change in thyroid hormone metabolism as well as their acitivities in tissue. A small subset of drugs including glucocorticoids, dopamine and dopamine agonists, somatostatine analogs and rexinoids cause suppression of TSH and central hypothyreoidism. This central hypothyroidism usually is not cllinically evident and its medical treatment is not necessery. Non- thyroidal illness syndrome (NTIS) also causes TSH suppression and central hypothyreoidism by complex mechanisms. It becomes clinically apparent if the treatment of NTIS is associated with
\end{abstract}

Prof.dr sc. med. Milica Medić-Stojanoska, Klinika za endokrinologiju, dijabetes i bolesti metabolizma, KC Vojvodine, 21000 Novi Sad, Hajduk Veljkova 1, e-mail: medsto@eunet.rs 
using glucocorticoids and dopamine and then possibilities possibilities of treatment this hypothreoidism should be considered. Different mechanisams by which these drugs cause central hypothyreoidism and their clinial relevance were analysed in this review.

Key words: drugs, TSH, cental hypothyroidism

\section{Uvod}

Mnogi lekovi koji se koriste u lečenju netireoidnih bolesti utiču na sekreciju i nivo tireoidnih hormona i TSH. Mehanizmi kojima deluju su raznovrsni i uključuju modifikaciju: hipotalamusno-hipofizne osovine, vezivanja tireoidnih hormona za cirkulišuće binding proteine, ulazak tireoidnih hormona u tkiva, metabolizam tireoidnih hormona preko dejodinacije, sulfatacije i glukoronidacije, kao i ekspresiju ili funkciju receptora tireoidnih hormona. Oni takođe mogu uticati i na resorpciju tireoidnih hormona u pacijenata s hipotireoidizmom koji su na terapiji L-tiroksinom $(1,2,3,4)$.

Glavni regulatori sinteze i sekrecije TSH su stimulatorni uticaji TRH i negativan uticaj cirkulišućeg nivoa tireoidnih hormona mehanizmom negativne povratne sprege. Drugi faktori, kao što su dopamin, somatostatin i leptin, samo modulišu TSH sintezu i sekreciju. Interakcija svih ovih faktora diktira shemu TSH sekrecije. TSH ima diurnalnu sekreciju s višim nivoima tokom noći i pulsnu sekreciju s relativno malim pikovima. Iako serumske kocentracije TSH fluktuiraju tokom dana, nivo cirkulišućeg TSH je stabilan.

Dijagnoza centralnog hipotireoidizma se postavlja na osnovu vrednosti TSH i/ ili fT4 ispod granice referentnih vrednosti. Ovi poremećaji ne moraju biti ispoljeni u blagoj pituitarnoj disfunkciji, kada su obično oko donje granice referentnih vrednosti, te ostaju nedijagnostikovani. Nivo sniženja TSH ne govori o težini centralnog hipotireoidizma. Sve ovo ukazuje na manjkavosti primene klasičnih tireoidnih testova u dijagnostici centralnog hipotireoidizma. Sekrecija TSH u pacijenata s hipopituitarizmom snižena je usled deficita TSH, ali je ona još uvek pod inhibitornom kontrolom cirkulišućeg fT4 mehanizmom povratne sprege. Eliminacijom fiziološke inhibicije fT4 na TSH sekreciju izračunavanjem TSH indeksa (TSHI), dobijaju se mnogo pouzdaniji podaci o prisustvu pituitarne disfunkcije i bilo koje patološke supresije TSH sekrecije (5). Primenom TSHI moguće je sigurnije otkrivanje TSH deficita, pa i u situacijama kada su vrednosti tireoidnih testova još uvek u rasponu referentnih.

Lekovi koji utiču na TSH ili tireoidnu funkciju na nivou hipotalamusa i/ili hipofize obuhvataju malu grupu lekova. To su najčešće glukokortikoidi, dopaminski agonisti, somatostatinski analozi, reksinoidi i, moguće, Carbamazepin (Oxocarbamazepin) i metformin (3). 


\section{Lekovi koji suprimuju serumske TSH nivoe}

\section{Glukokortikoidi}

Poznato je da glukokortikoidi deluju na nivo TSH u humanoj populaciji. Ispitivanja su potvrdila da fiziološki nivoi hidrokortizona imaju značajnu ulogu u održavanju diurnalnog ritma sekrecije TSH s nižim nivoima ujutro i višim tokom noći $(6,7)$. Egzogeno davanje glukokortikoida i endogena, hiperkortiozolemija usled Cuchingovog sindroma ili endogene depresije, praćena su supresijom TSH. To potvrđuje da glikokortikoidi dovode do centralnog hipotireoidizma, ali on nije kinički manifestan. $\mathrm{Na}$ osnovu rezultata ranijih studija $\mathrm{s}$ akutnim davanjem glukokortikoida u većim dozama, kao i drugih $(8,9)$, postojalo je mišljenje da je supresija nivoa TSH prisutna samo posle davanja suprafizioloških doza glikokortikoida. Međutim, Hangaard i sar. (10) su u svojoj studiji na pacijentima s Adisonovom bolesti pokazali da ne samo visoke doze hidrokortizona, već i one koje dovode do normalnog serumskog nivoa kortizola, vode progresivnom padu nivoa TSH. Sniženje nivoa TSH je dozno zavisno. Deksametazon u dozi od $0,5 \mathrm{mg}$ ili manjoj snižava TSH nivoe, dok $30 \mathrm{mg}$ prednizona signifikantnije smanjuje nivo TSH (2). Mehanizam kojim glikokortikoidi snižavaju nivo TSH uključuje supresiju lučenja TSH od strane tireotropnih ćelija hipofize putem protein kinaza C i proteina annexin 1 (11). Međutim, danas se smatra da je glavni mehanizam kojim glukokortikoidi suprimuju TSH, inhibicija hipotalamusne sekrecije TRH glukokortikoidima. TRH neuroni, smešteni u paraventrikularnom nuklusu hipotalamusa (PVN), uključeni su u neuroendokrinu regulaciju hipotalamusno-hipofizno-tireoidne osovine. Na ovim neuronima je dokazano prisustvo glukokortikoidnih receptora, kao i glukokortikoid-responsive elementa na TRH genu (12). Alkemade i saradnici (13) su merili TRH mRNA ekspresiju u humanom hipotalamusu i dokazali da pacijenti lečeni glukorkotikoidima imaju značajno nižu ekspresiju TRH mRNA u odnosu na pacijente koji nisu dobijali glukokortikoide. Danas se smatra da je to glavni mehanizam supresivnog delovanja glukokortikoida na TSH.

U zaključku, glukokortikoidi mogu snižavati TSH i smanjivati sekreciju TSH direktnim delovanjem na TRH neurone u hipotalamusu. Dugotrajno davanje visokih doza glikokortikoida ili enogena hiperkortiozolemija (Cushing, endogene depresije i dr.) nisu praćeni klinički manifestnim centralnim hipotireoidizmom.

\section{Dopamin i dopaminski agonisti}

Na eksperimentalnom modelu, i studije u humanoj populaciji pokazale su da dopamin ima različito dejstvo na hipofizu i hipotalamus kada je u pitanju regulacija sekrecije TSH. Aktivacijom dopaminskih D2 receptora (D2R) na tireotropnim ćelijama hipofize inhibiše sintezu i sekreciju TSH. Ovim putem dopamin smanjuje 
amplitudu pulsa, ali ne utiče na frekvenciju pulsa (14). Uticaj dopamina na TSH sekreciju dokumentovan je u studiji na zdravim ženama, kada je blokadom D2R metoclopramidom došlo do skoka u 24h pulsatilnoj sekreciji TSH (15). Međutim, na nivou hipotalamusa dopamin ima suprotan efekat. Naime, vezivanjem za D2R na tireotropnim neuronima PVN u hipotalamusu dopamin stimuliše sekreciju TRH. Ovaj stimulatorni uticaj na nivo hipotalamusa je nadvladan prethodnim, tako da dominira inhibicija TSH sekrecije (14).

Bromokriptin, dopaminski agonista, ima ista dejstva na tireotropne ćelije hipofize. Vezivanjem i aktivacijom D2R inhibiše sintezu i sekreciju TSH u tireocitima. Na taj način snižava bazalnu sekreciju i pulsne amplitude TSH, dok ne utiče na frekvenciju pulsa $(3,14,16)$. Ova inhibicija sekrecije TSH je dozno zavisna. Bromokriptin, slično dopaminu, preko D2R na TRH neuronima PVN u hipotalamusu stimuliše sekreciju TSH. Međutim, inhibicija TSH sekrecije na nivou hipofize ipak nadvladava stimulatorni efekat na nivou hipotalamusa. Pretpostavka je da bromokriptin povećava biološku aktivnost izlučenog TSH putem povećanog stvaranja TRH. Bromokriptin takođe smanjuje simpatičku aktivnost i povećava osetljivost tireocita na TSH (14). Navedeno bi možda moglo biti objašnjenje za odsustvo promene nivoa tireoidnih hormona u slučaju signifikantnog sniženja TSH tokom terapije bromokriptinom. Pored direktnog dejstva na sekreciju TSH, bromokriptin ima indirektno dejstvo preko leptina. Naime, studije na gojaznima i druge pokazale su da bromokriptin snižava nivo leptina, što takođe doprinosi daljem sniženju TSH (14). Dugotrajna terapija bromokriptinom kod pacijenata s makroprolaktinomom nije praćena razvojem manifestnog hipotireoidizma.

U zaključku, dopamin i dopaminski agonisti smanjuju sintezu i lučenje TSH u hipofizi preko D2R, iako istim mehanizmom stimulišu TRH sekreciju na nivou hipotalamusa. Terapija ovim lekovima per se, u odsustvu teških netireoidnih bolesti, nije praćena manifestnim centralnim hipotireoidizmom i ne zahteva supstitucionu terapiju tireoidnim hormonima.

\section{Somatostatinski analozi}

Somatostatin i somatostatinski analozi direktno inhibišu sekreciju TSH u tireotropnim ćelijama hipofize aktivacijom somatostatinskih receptora podtip 2 i 5 (SST2 i SST5), koji se nalaze na površini ovih ćelija (14). Koriste se kao terapija u pacijenata s rezistencijom na tireoidne hormone, jer snižavaju nivoe TSH, ili u lečenju pacijenata s TSH sekretujućim adenomom koji nije hirurški izlečen (17). Davanje somatostatina zdravim volonterima pokazalo je da somatostatin dovodi do smanjenja i pulsne amplitude i frekvencije pulsa TSH sekrecije (18). Dugodelujući somatostatinski analozi kod zdravih volontera suprimovali su serumski TSH i smanjili TSH odgovor stimulisan TRH-om (14). Jednogodišnja studija sa primenom somatostatina u prevenciji 
dijabetesne retinopatije pokazala je samo umereno suprimovane nivoe TSH, bez manifestnog centralnog hipotireoidizma (19). Praćenje sekrecije TSH u pacijenata s akromegalijom lečenih oktreotidom pokazala su da nakon 1 meseca dolazi do sniženja TSH i smanjenog TSH odgovora na stimulaciju TRH-om. Nakon 6 meseci terapije nije bilo više supresije bazalne TSH sekrecije, ali je TSH odgovor na TRH bio i dalje snižen. Vrednosti T4 su bile nepromenjene, dok su vrednosti T3 bile niže s višim vrednostima reverznog T3, sve vreme ispitivanja. To sugeriše da bi oktreotid mogao imati direktan i indirektan uticaj na metabolizam tireoidnih hormona (20).

Somatostatin i somatostatinski analozi direktno suprimuju sintezu i sekreciju TSH u tireotropnim ćelijama hipofize aktivacijom SST2 i SST5 receptora. Ovi efekti su tranzitorni i nisu praćeni klinički manifestnim centralnim hipotireoidizmom, niti je potrebna supstituciona terapija tireoidnim hormonima.

\section{Rexinoidi}

Rexinoidi ili retinoidi, koji deluju interakcijom s nuklearnim hormonskim receptorom retinoid X receptor (RXR), nova su grupa lekova, derivati vitamina A. RXR ima sposobnost stvaranja heteodimera s drugim nuklearnim transkripcionim faktorima (receptorom za tireoidne hormone -TR, retinoid acid receptorom - RAR, vitamin D receptorom - VDR, peroxizome proliferator -aktivisani receptor - PPAR i hepatični X receptor. Zbog toga imaju mogućnost delovanja na transkripciju raznih ciljnih gena direktno ili preko svojih proteinskih partnera. Bexarotene (Targetin) je jedini za sada prihvaćeni rexinoid za kliničku primenu. Koristi se za lečenje kutanog T ćelijskog limfoma (CCTL), a u razmatranju su njegove indikacije za lečenje nekih malignih bolesti (pluća, dojke, štitaste žlezde) i metaboličkih poremećaja (dijabetes mellitusa i gojaznosti).

Dokazano je da Bexarotene izaziva klinički manifestan centralni hipotireoidizam, sa značajnim sniženjem TSH, ali i tireoidnih hormona, pre svega T3. Ovaj hipotireoidizam se razvija već posle dve nedelje primene i reverzibilan je. Od 27 pacijenata s CCTL, koji su lečeni visokim dnevnim dozama bexarotena, 26 je imalo suprimovan TSH, a 19 klinički manifestan centralni hipotireoidizam (21). Studijama in vitro (22) i eksperimentalnim studijama $(22,23)$ dokazano je da bexaroten izaziva centralni hipotireoidizam supresijom sinteze TSH subjedinica smanjujući aktivnost gena TSH $\beta$ subjedinice u tireotropnim ćelijama, dok ne utiče na sekreciju TSH iz ovih ćelija. Studija na zdravim volonterima (24) pokazala je da bexaroten ne dovodi do centralnog hipotireoidizma indirektno, jer sekrecija kortizola i prolaktina nije bila alterisana tokom ove studije. Takođe je isključen i poremećaj TRH sekrecije od strane hipotalamusa. To potvrđuje da je ovaj centralni hipotireodizam posledica direktne supresije gena koji kodira sintezu TSH subjedinice u tireotropnim ćelijama hipofize, odnosno da je tireotropno specifičan. Macchia i saradnici (25) su u eksperimentalnoj 
studiji na miševima pokazali da je centralni hipotireoidizam izazvan reksinoidima bio praćen gubitkom tireoidnog receptora $\beta$ (TR $\beta$ ) na tireotropnim ćelijama, koji posreduje uticaj tireoidnih hormona na tireotropne ćelije. Ovo saznanje i prethodna sugerišu da reksinoidi imaju T3-nezavisan efekat na tireotropne ćelije, što bi moglo imati terapijskih implikacija. Naime, pruža se mogućnost njihove terapijske primene kod pacijenata sa sindromom rezistencije na tireoidne hormone i TSH sekretujućim adenomom hipofize. Potvrđeno je da reksinoidi imaju uticaja i na metabolizam tireoidnih hormona povećavajući njihov klirens, direktno ili indirektno, utičući na proces dejodinacije, sulfatacije i moguće glukoronidacije $(3,24)$.

Reksinoidi dovode do izražene supresije TSH sekrecije i klinički manifestnog hipotireoidizma, koji je reverzibilan. Tokom terapije ovim lekovima neophodno je sprovođenje supstitucione terapije L-tiroksinom.

Drugi lekovi koji mogu uticati na nivo TSH

Antiepileptički lekovi, kao što su carbamasepin, oxacarbamasepine i valproična kiselina, ubrzavaju metabolizam tireoidnih hormona preko hepatičkog enzimskog sistema P450. Međutim, oni mogu dovesti i do centralnog hipotireoidizma menjajući osetljivost pituitarnih ćelija na uticaj tireoidnih hormona mehanizmom povratne sprege (26).

Metormin može dovesti do sniženja TSH (27). Ovo je dokazano u pacijenata s tipom 2 dijabetesa i primarnim hipotireoidizmom na supstitucionoj terapiji L-tiroksinom, ali ne i u pacijenata s normalnom tireoidnom funkcijom $(3,27)$. Tačan mehanizam ovog delovanja nije jasan, moguće suptilnim promenama nivoa FT4 usled poremećene resorpcije datog L-tiroksina.

\section{Netireoidne bolesti (Non-thyroidal illness syndrome- NTIS ) i centralni hipotireoidizam}

Akutne i hronične bolesti, organske ili psihijatrijske, često su praćene poremećajima neuroendokrinog sistema. Pored poremaćaja hipotalamusno-hipofizno-adrenalne osovine, one dovode i do disfunkcije hipotalamusno-hipofizno-tireoidne osovine (HHT). Promene koncentracije tireoidnih hormona i TSH, koje nastaju tokom ovih bolesti, a koje nisu posledica poremećaja funkcije ili oboljenja same štitaste žlezde nazivaju se non-thyroidal illness syndrome (NTIS). Još uvek nije jasno da li se radi o patološkim poremećajima koji zahtevaju supstitucionu terapiju tireoidnim hormonima ili je u pitanju adaptivni odgovor na stres s ciljem da se smanji metabolička aktivnost, što može biti korisno za preživljavanje bolesnika (28).

Najčešći poremećaji su nizak ukupni T3 (TT3), dok ukupni T4 (TT4) može biti normalan, snižen ili povišen. U oko 3\% bolesnika hospitalizovanih bolesnika s akutnim oboljenjem TSH je $<0,1 \mathrm{mU} / 1$, a oko $75 \%$ ovih pacijenata ima snižen TSH zbog NTIS ili upotrebe glukokortikoida ili dopamina u lečenju ovih bolesnika. U jedinicama 
intenzivne nege prevalenca poremećaja nivoa tireoidnih hormona je visoka, preko $70 \%$ pacijenata ima snižen TT3 i oko 50\% snižen TT4 (29). Promene nivoa slobodnih tireoidnih hormona promenljive su i zavise od primenjene metodologije.

Mehanizmi kojima NTIS dovodi do poremećaja tireoidne funkcije brojni su i uključuju i modifikaciju HHT osovine.

Centralni hipotireoidizam je čest poremećaj u NTIS i uglavnom je praćen normalnim ili čak sniženim nivoom TSH, iako je cirkulišući T3 nizak. Noćni skok sekrecije TSH je niži, kao i pulsne amplitude. Moguća je i sekrecija biološki manje aktivnog TSH. Nizak TSH u NTIS je posledica promena u set point- $u$ HHT i smanjenoj hipotalamusnoj sekreciji TRH, kao i direktnog inhibitornog dejstva inflamatornih citokina na pituitarne tireotropne ćelije.

Specifična grupa TRH neurona, smeštenih u paraventrikularnom nukleusu (PVN), odgovorna je za sintezu TRH. Oni čine fokus set point-a HHT osovine. U centralnom hipotireoidizmu, usled NTIS, dolazi do smanjenja ekspresije TRH gena u PVN, što je praćeno smanjenjem sinteze i sekrecije hipotalamusnog TRH. Glavni uzroci smanjene hipotalamusne sekrecije TRH u NTIS najverovatnije su malnutricija i sekrecija inflamatornih citokina. TRH neuroni PVN su inervisani neuronima nucleus arcuatus-a, koji sadrže $\alpha$ melanostimulišući hormon ( $\alpha$ MSH), neuropeptid Y (NPY), agouti related protein (AGRP) i inhibitorni neurotransmiter GABA. NPY i AGRP inhibišu gensku ekspresiju TRH, što može biti prevenirano leptinom, dok je $\alpha$ MSH stimuliše. Tokom malnutricije, zbog pada nivoa leptina, dominiraju inhibitorni efekti NPY i AGRP na TRH gensku ekspresiju. Sniženje nivoa leptina dovodi i do smanjenog stimulacionog dejstva $\alpha \mathrm{MSH}$. Drugi uzrok smanjene sekrecije TRH u hipotalamusu je lokalni hipertireoidizam. T3 ima važnu ulogu u inhibiciji hipotalamusne TRH sekrecije mehanizmom povratne sprege. TRH neuroni nemaju mogućnost konverzije T4 u T3. Konverzija T4 u T3 se događa u tireocitima, glija ćelijama, koje oblažu dno treće moždane komore, koje šire svoje produžetke duboko u hipotalamus. U sepsi i traumi povećana je aktivnost D2 jodotiroin dejodinaze, koja konvertuje T4 u T3, kao i D3 jodotironin dejodinaze, koja smanjuje metabolizam T3, tako da se produkcija T3 povećava i razvija se lokalni hipertireoidizam. Iz tanacita preko cerebrospinalne tečnosti ili krvotokom visoki nivoi T3 dolaze do TRH neurona i smanjuje se stvaranje TRH u hipotalamusu (30).

Lokalno stvoreni citokini mogu imati direktan inhibitorni efekat na TSH sekreciju u tireotropnim ćelijama hipofize (31). Periferno produkovani proinflamatorni citokini u pacijenata sa sepsom, traumom ili autoimunim bolestima (IL-6, TNF $\alpha$ i interferon $\gamma)$ takođe suprimuju sekreciju TSH iz tireocita.

Centralni hipotireoidizam u okviru NTIS nije klinički manifestan i reverzibilan je. Naime, tokom oporavka dolazi do porasta nivoa TSH. Ponekad TSH može biti i iznad granice normalnih vrednosti, što se može pogrešno interpretirati kao primarni hipotireoidizam. Međutim, ovaj skok TSH samo prethodi porastu nivoa T4 i T3 u fazi rekonvalescencije. 
S obzirom na to da su ova oboljenja i stanja praćena često primenom glukokortikoida i/ili dopamina, prisutni centralni hipotireoidizam može postati klinički manifestan. Postavlja se pitanje da li je u ovim situacijama potrebno njegovo lečenje.

\section{Zaključak}

Lekovi koji suprimuju sekreciju TSH (glukokortikoidi, dopamin i dopaminski agonisti, somatostatinski analozi, rexinoidi) deluju na nivou hipotalamusa i/ili hipofize. Centralni hipotireoidizam, izazvan ovim lekovima, nije klinički manifestan i nije potrebna supstituciona terapija tireoidnim hormonima. Samo reksinoidi dovode do klinički ispoljenog hipotireoidizma koji zahteva terapiju. NTIS je takođe praćen supresijom TSH i klinički asimptomatskim hipotireoidizmom. Primena glukokortikoidne terapije i dopamina, koja je česta u ovim netireoidnim bolestima, rezultira klinički jasnim hipotireoidizmom gde se, možda, nameće potreba lečenja hipotireoidizma.

\section{Literatura}

Surks MI, Sievert R. Drugs and thyroid function. New England Journal of Medicine, 1995, 333 (25): 1688-1694.

Lania A, Persani L, Beck-Peccoz P. Central Hypothyreoidism.Pituitary, 2008, 11: 181-186.

Bryan RH. Drugs that supress TSH or cause central hypothyreoidizam. Best Practice \& Research Clinical Endocrinology \& Metabolism, 2009, 23: 793-800.

Ćurić N. Doprinos imunoradiometrijskog određivanja tireostimulišućeg hormona funkcionom ispitivanju štitaste žlezde. Magistarski rad, Medicinski fakultet Novi Sad, 1991.

Jostel A, David W, Ryder J, Shalet SM. The use of thyroid function tests in the diagnosis of hypopituitarism: definition and evaluation of the TSH index. Clinical Endocrinology, 2009, 71: 529-534.

Samuels MH, McDaniel PA. Thyrotropin levels during hydrocortisone infusions that mimic fasting-induced cortisol elevations: a Clinical Research Center Study.The Journal of Clinical Endocrinology and Metabolism, 1997, 82 (11) : 3700-3704.

Samuels MH. Effects of variation in physiological cortisol levels on thyrotropin secretion in subjects with adrenal insufficiency: a Clinical Research Center Study. Journal of Clinical Endocrinology and Metabolism, 2000, 85 (4): 1388-1393.

Samuels MH, Luther M, Henry P, Ridgway EC. Effects of hydrocortisone on pulsatile pituitarz gylicoprotein secretion. Journal of Clinical Endocrinology and Metabolism, 1994, 78: 211-215.

Samuels MH. Effects of Metyrapone Administration on Thyroid Secretion in Healthy Subjects - A Clinical Research Center Study. Journal of Clinical Endocrinology and Metabolism, 2000, 85 (9): 3049-3052. 
Hangaard J, Andersen M, Grodum E, Koldkjaer O, Hagen C. Pulsatile thyrotropin secretion in patients with Addison's Disease during variable glucocorticoid therapy. Journal of Clinical Endocrinology and Metabolism, 1996, 81: 2502-2507.

John CD, Chrustian HC, Morris JF. Kinase-dependent regulation of the secretion of thyrotropin and luteinising hormone by glucocorticoids and annexin 1 peptides. Journal of Neuroendocrinology, 2003, 15 (10): 946-957.

Cintra A, Fuxe K, Wikstrom Ac et al. Evidence of Tyrotropin-releasing hormone and glucocorticoid receptor-immunoreactive neurons in various preoptic and hypothalamic nuclei of the male rat. Brain Research, 1990, 506 (1): 139-144.

Alkemade A, Unmehopa UA, Wiersinga WM, Swaab DF, Fliers E. Glucocorticoids decrease Thyrotropin - Releasing Hormone Messenger Ribonucleic Acid Expression in the Paraventricular Nucleus of the Human Hypothalamus. Journal of Clinical Endocrinology and Metabolism, 2005, 90 (1): 323-397.

Kok P, Roelfsema F, Frolich M, van Pelt J, Meinders EA, Pijl H. Bromocriptine reduces Augmented Thyrotropin Secretion in Obese Premenopausal Women. Clinical Endocrinology and Metabolism, 2009, 94 (4): 1176-1181.

Rossmanith WG, Mortola JF, Laughlin GA, Yen SS. Dopaminergic control of circadian and pulsatile pituitary thyrotropin elease in women. Journal of Clinical Endocrinology and Metabolism, 1988, 67: 560-564.

Bonomo IT, Lisboa PC, Passos MCF, Alves SB, Reis AM, de Moura EG. Prolactin inhibition at the end of lactation programs for a central hypothyroidism in adult rat. Journal of Endocrinology, 2008, 198:331-337.

Elston MS, Conaglen JV. Clinical and biochemical characteristics of patients with thyroid - stimulating hormone - secreting pituitarz adenomas from one New Zeland centre. Internal Medicine Journal, 2010, 40: 214-219.

Samuels MH, Henri P, Ridgway EC. Effects of dopamine and somatostatin on pulsatile pituitary glycoprotein secretion. Journal of Clinical Endocrinology and Metabolism, 1992,74 (1): 217-222.

Kirkegard C, Norgaard K, Snorgaard O. et al. Effect of one year continuous subcutaneus infusion of somatostatin analogue, octreotide, on early retinopathy, metabolic control and thyroidal function in Type 1 (insulin -dependent) diabetes mellitus. Acta Endocrinologica, 1990, 12286 ): 766-772.

Roelfsema F, Frolich M. Pulsatile thyrotropin release and thyroid function in acromegalics before and during subcutaneous octreotide infusion.The Journal of Clinical Endocrinology and Metabolism, 1991, 72 (1): 77-82.

Sherman SI, Gopal J, Haugen BR, Chiu AC, WhaleyKNP, Duvic M. Central hypothyroidism asociated with retinoid $\mathrm{X}$ receptor selective ligands. New England Journal of Medicine, 1999, 340: 1075-1079.

Sharma V, Hays WR, Wood WM, FugazhenthiU, StGermain DI, Bianco AC, Krezel W, Chambon P, Haugen BR. Effects of rexinoids on thyrotrope function and the hypothalamic-pituitary axis. Endocrinology, 2006,147: 1438-1451.

Liu S, Ogilvie KM, Klausing K, Lawson MA, Jolley D, Li D, Bilakovics J, Pascual B, Hein N, Urcan M, Leibowitz MD. Mechanism of selective rexinoid X receptor agonist-induced hypothyreoidism in the rat. Endocrinology, 2002, 143: 2880-2885. 
Golden WM, Weber KB, Hernandez TI, Sherman SI, Woodmansee WW, Haugen BR. Single dose Rexinoid Rapidly and Specifically Suppress Serum Thyrotropin in Normal Subjects. Journal od Clinical Endocrinology and Metabolism, 2007, 92(1): 124-130.

Macchia PE, Jiang P, Zuan YD, Chandarardna RA, Weiss RE, Chassande O, Samarut J,Reffetof $\mathrm{S}$, Burant CF. RXR receptor agonist suppression of thyroid function, central effects in the absence of thyroid hormone receptor. American Journal of Physiology Endocrinology and Metabolism, 2002, 283: 326-331.

Miller J, Carney P. Central hypothyreoidism with oxacarbasepine therapy. Pediatrix Neurology, 2006, 34 (3): 242-244.

Vigersky RA, Filmore-Nasar A, Glass AR. Thyrotropin suppression by metformin.The Journal of Clinical Endocrinology and Metabolism, 2006, 91(1): 225-227.

Fliers E, Alkemade A, Wiersinga WM. Thy hypothalamic-pituitary-thyroid axis in critical illnes. Best Practice and Research. Journal of Clinical Endocrinology and Metabolism. 2001,15: 453-464.

Ray Dc, Macduff A, Drummond GB, Wilkinson E, Adams B, Beckett GJ. Endocrine measurements in survivors and non-survivors from critical illnesses. Intensive Care Medicine, 2002, 28: 1301-1308.

Warner MH, Beckett G. Mechanisms behind the non-thyroidal illnes syndrome: up date. Journal of Endocrinology, 2010, 205: 1-13.

Boelen A, Kwakkel J, Thijjssen -Timmer DC, Alkemade A, Fliers E, Wiersinga WM. Simultaneous changes in central and peripheral components of the hypothalamus-pituitarythyroid axis in lipopolysacharide-induced acute illness in mice. Journal of Endocrinology, 2004, 182: 315-323. 